\section{nature materials}

www.nature.com/naturematerials

\title{
The business of science
}

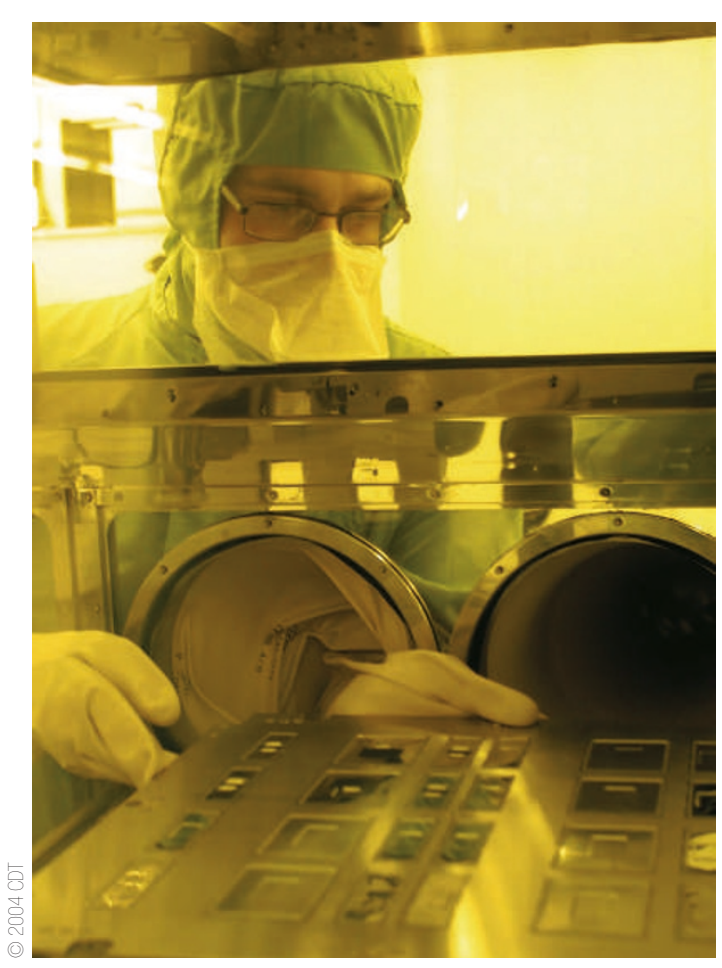

SPIN-OFF COMPANIES OFFER A CHANCE TO RAPIDLY COMMERCIALIZE RESEARCH.
It's every poorly paid materials scientist's dream: turning your scientific discovery into a commercial success. And it's happened for Yet-Ming Chiang of Massachusetts Institute of Technology, who authored a 2002 article in Nature Materials ${ }^{1}$ on high-capacity storage cathodes for rechargeable lithium batteries. He founded the company A123Systems to exploit the technology reported in his paper, and within four years of publication, the company has $\$ 100$ million worth of orders in hand, including a deal with power-tool giant Black \& Decker.

Commercially interesting advances from academic materials science research are increasingly being protected by patents and exploited by spin-off companies. In most cases, like Chiang's, the company is started by the lead researcher and based on the research originally carried out within the university group. Researchers in the US were quick to realize the potential advantages of this approach after Congress passed the Bayh-Doyle act in the 1980s, allowing the patenting of statefunded research. The UK was relatively slow to join the initiative, but is now keen to exploit this course of action as much as possible: in 2002, UK universities created 50 spin-offs for every billion dollars of research, compared with 15 in the US ${ }^{2}$. Japan has also experienced rapid growth in this area, and, despite the traditional lack of venture capital, reported US\$1.8 billion investment into start-ups in 2005 compared with US $\$ 22$ billion in the US and US $\$ 13$ billion in Europe in $2004^{3}$.

Quantity, however, doesn't necessarily directly translate to quality, or indeed success. With universities increasingly under pressure to ensure that their research output is commercially exploited ${ }^{4}$ and research councils preferentially funding projects with a higher chance of commercialization ${ }^{5}$, there emerges a distinct danger of too much focus on creating spin-offs without sufficient prior assessment of their potential. Indeed, there is an ongoing debate in the UK on whether too much emphasis is put on spin-off companies instead of exploring the option of licensing patents on technology to established companies ${ }^{3}$. Licensing offers some of the benefits of the spin-off, but with less risk attached.

Certainly, the spin-off option offers many potential gains for the academics and their universities. These can be more extensive than simple financial returns, which may actually be quite small for the academic once the university and several rounds of investors have taken their share. One of the most notable advantages for research is the potential benefit for the underlying science - as highlighted by Richard Friend in our interview on page 926 of this issue ${ }^{6}$. Advances in device engineering achieved in his spin-off company, Cambridge Display Technology, facilitated fundamental measurements on organic semiconductors in his research group. In this way, fundamental research can receive a bonus of indirect funding from investments into the company. Other advantages include jobs for graduates and others within the local community, investment of the money generated back into the university as a whole, and more rapid development of technological advances into useful products for the marketplace.

The fact remains, however, that starting a company is not wholly consistent with the traditional objectives of scientists in academia. A scientist's basic training doesn't include the art of running a business - and as Xiaogang Peng discusses in his Commentary on page 923 of this issue ${ }^{7}$, starting a company requires a very different set of skills from those used in the lab. Even discovering an entirely novel technology is not necessarily enough to ensure a successful business; the differences between a novel discovery and developing a product that customers need or want to buy are enormous.

There is an increasing desire and expectation to make commercial success of academic research. This is understandable, given the potential gains demonstrated by companies like A123Systems, and universities should undoubtedly provide support for academics with a strong drive to commercialize their research. However, encouraging academics to spin-off research without having a solid business plan and support in place has the potential to be damaging for all. Whether an academic wishes to pursue this option should be a carefully weighed choice, not a requirement in their career. 